\title{
Impacts of Tax Incentives on Corporate Financial Performance: The Case of the Mechanical and Electrical Industries Sector in Tunisia
}

\author{
Hedia Teraoui (Corresponding author) \\ High School of Business of Tunis, University of Manouba, 2010. Tunisia \\ E-mail: teraouihedia@hotmail.com \\ Amira Kaddour \\ High School of Business of Tunis, University of Manouba, 2010.Tunisia \\ E-mail: amira.kaddour@hotmail.com \\ Jameleddine Chichti \\ High School of Business of Tunis, University of Manouba, 2010.Tunisia \\ E-mail: jameleddine.chichti@esct.rnu.tn \\ Jaleleddine Ben Rejeb \\ High Institute of Management of Sousse, University of Sousse \\ E-mail: jaleleddine.benrejeb@esct.rnu.tn
}

Received: June 1, 2011

Accepted: July 7, 2011

Published: November 1, 2011

doi:10.5539/ijef.v3n6p117

URL: http://dx.doi.org/10.5539/ ijef.v3n6p117

\begin{abstract}
Since 1970, the debate on the relationship between taxation and corporate financial performance has intensified during these last decades. The aim of this paper is to examine this relationship thesis. If it is acknowledged that incentives become a widespread method in the world in order to promote the investment, the paper contribute to the literature by testing the effects of an inciting taxation on the profitability of the Tunisian exporting firms in the sector of the Mechanical and Electric Engineering Industries. The empirical study, conducted on a sample of 60 firms, reports the following results: the estimation of the benefit and the output conclude that an increase of taxation affects negatively these two financial criteria of the performance. In addition to the use of temporal data, an approach based on an investigation by questionnaire confirms the results found at the time of the other approaches.
\end{abstract}

Keywords: Tax export, Taxation, Incentives, Profitability, Economic performance, Financial performance, Non financial performance

\section{JEL Classification: F10, E62, L25}

\section{Introduction}

The study of the relationship between tax incentives and the performance of the firms, has known a peak during these last decades, mainly with the works of (Yonah (2006) and Gurria (2009)). The authors' main thesis is that as a tool of government policy, tax incentives can be adopted to attract investors who want to increase the profitability of their businesses to promote investment. Faced to the fury of global competitiveness, several countries have implemented a proactive policy's export promotion in order to be adapted to the various changes imposed by the environment. In the context of this policy, the fiscal instrument occupies a prominent place among the other incentives adopted by these countries to conquer foreign markets and to face competition. Indeed, Tunisia, like many developing countries has raised the challenge by focusing on export promotion in order to facilitate penetration of domestic products to foreign markets and be more competitive.

The concept of incentives has been absent from economic theory to the seventies (Laffont et Tirole (1991)). Houdebine and Bensaid (1999) showed that several factors may influence the decision to invest abroad: taxation, the level of skills, infrastructure and agglomeration effects. In 2008, the OECD report states that the tax policies contribute to support for FDI by facilitating access to foreign markets and achieve economies of scale. The best example of successful tax incentives is the "Mauritian miracle": the generous tax advantages offered by Mauritius has greatly contributed to attracting investment in the island. In 2007, Hoyt argues that the tax reduction is the most important reason that encourages investors to invest offshore because it allows them to improve their economic and 
financial performance.

We investigate the impacts of taxation on the financial performance of the firm of the Tunisian exporting firms in the sector of the Mechanical and Electric Engineering Industries. The econometric adjustment of indicators of performance (net income and output) according to its determinants shows a negative and statistically significant tax rate on the performance of exporting firms in the sector of EMI. The estimate by the method of least squares (GLS) shows that taxation affects the financial performance of the firm. Indeed, all things being equal, a change in tax rates by $1 \%$ would decrease from $0.31 \%$ of the output of the company. Similarly, an increase of the taxe rate of $1 \%$ decreases of $0.07 \%$ of net profit. Besides the use of temporal data and econometric tool, an approach based on a questionnaire survey studied the perceptions of CFOs of 60 firms nearly $3 \%$ of the total population of companies studied. Using a descriminant analysis has identified the variables which discriminated the two classes of firms defined by using cluster analysis. The examination of the results of the estimate of a Logit model show the significant association of the dependent variable (export performance) with the predictors listed above in the context of a discriminant analysis in which we remember: tariffs, having benefited from tax, having benefited from these advantages for the acquisition of equipment and ongoing business, incentives are a key motivating factor and finally the current system of tax benefits suffers from inadequacies and shortcomings.

The remainder of this paper is organized as follows: Section 2 presents a brief review of the literature and discusses the impacts of tax incentives on the financial performance of the firm. Section 3 identifies quantification of the impacts of tax incentives on the performance of the firm/ the model specification, variables definitions, econometric approaches and reports the major empirical results. Section 4 concludes the paper.

\section{Theoretical background}

An extensive literature has produced convincing results concerning the impact of tax incentives on the investment. Stiglitz (1973), Sandmo (1974), King (1974) and Boadway (1979) have extended the Jorgenson's classical model of investment behavior (1967) to determine the effects of taxation on investment decisions. By emphasizing the importance of tax policy and administration for domestic and international investors, Stone (2008) proceeds by comparing the advantages and disadvantages of tax incentives, he said that taxation affects the international competitiveness. By treating the relationship between fiscal policy and financial policy within the firm and its impact on growth, Strulik (2003) conducted by comparing the policies of firms in different economic contexts. The impacts identified by the author are obtained by using a general equilibrium model based on production functions of Cobb Douglas, detailing the account of the firm (based on investment, employment, result operation ...). The results found by the author shows that a reduction of $10 \%$ tax would increase the firm gain of $5 \%$. The author stresses that the standard models (not taking into account the economy as a whole) overestimate the effect of the tax reform on investment and profitability since they neglect the financial adjustments of the company. Jochen A. Birk (2006), using statistics provided by a number of OECD countries argue that tax reform can reduce unemployment and improve economic growth by improving the financial performance of the firm. Tax incentives are a stimulating factor of the location of foreign direct investors. Through a survey by questionnaire on a sample of 600 executives of large multinational firms from seven countries including Honkong Singapore, Australia, Canada, PR China, U.S. and UK, Simmons (2003) showed that there is a significant positive correlation between indices of the attractiveness of the tax system of countries selected and the size entries of FDI.

However, in a turbulent economic environment characterized by multiple mutations, the company is increasingly facing a tougher competitive space, due to the enlargement of its scope of activities and the interconnectedness of different markets. To adapt to this environment and cope with this competition, the company must be able to free the various economic and strategic challenges to ensure its sustainability, among other things is to be competitive and improve its economic and financial performance. In the world of management science, reflections on the performance have been the source of many questions. Indeed, Lebas (1995b) considers that "there is no universal and comprehensive definition of performance and yet every business must define the term for its internal and external communication." Moreover, the criteria for evaluating performance contribute to the lack of a universal definition. Indeed, in the 60s, the measure of performance was the size (sales, assets). Then in the 70s, it is called net income or earnings per share to evaluate performance. Later in the $80 \mathrm{~s}$, the performance evaluation is done through the company's ability to generate liquidity. Recently, it equates to the performance ability to create value. So when it comes to measuring performance, economists tend to use the benefit as this measure allows the component to impregnate and "creativity" (the income component) and component "discipline" (component cost) necessary to follow a market economy. Relative to income, the measure of performance is more cost effective to the extent that costs are more stable. Frydman (1999) argues that it is the measure most used by managers who can form an idea on costs and the costs that the firm will bear. Clearly, tax is a heavy cost to the company wishing to reduce its expenses. Reduce the tax will obviously reduce business costs which can improve its financial performance. 
Several criteria and indicators are used to measure the performance of exporting firms. The multitude of them clearly demonstrates the consensus on the multidimensional nature of the concept of performance. From an analysis of relevant literature of the last twenty years, Dennis (1990) distinguishes between two approaches to measurement: a quantitative approach using criteria that measure the size of exports and a second approach using qualitative criteria that measure the perception of success in foreign markets. In the same vein, Ramangalahy (2002) reports three categories of indicators must be taken to determine the performance of exporting firms: quantitative indicators measuring the export performance and qualitative indicators measuring the strategic performance of companies. The first criteria for evaluating performance emerges from the litterature namely, the financial criteria such us profitability, solvency and liquidity... it is important to note that traditional measures are no longer adapted to the current context where competition has taken on new forms (quality, time ,...). This failure in financial systems for measuring the performance was highlighted by several studies. In 1995, Lebas argues that it is impossible to reduce the performance of the company to the only the information provided by the operating income or net book value (NBV) because it is the result of a sequence operations. The financial measures reflect the results of measures taken in the past (Kaplan and Norton (2001), Shank and Govindarajan (1995), etc.). Therefore, financial measures haven't a proactive quality and do not indicate how to improve performance. Thus, financial measures do not take into account the intangible asset so that currently, the value of the company is increasingly explained by other factors such as innovation, personnel, quality, certification, etc.

The exclusive use of financial performance measures has spawned a large gap in the systems of performance measurement. The non-financial measures were introduced to implement the missing piece of the puzzle of performance. These measures have proved a great contribution in evaluating the performance of the company. Indeed, Ittner and Larcker (2003) consider that the main objective of non-financial performance is to complete the picture provided by the traditional financial information. They show that non-financial measures of performance are numerous. Firstly, quality is now the ultimate weapon and the underlying foundation of the performance of competitive firms. It may be regarded as a product of the excellence compared to current market alternatives. Then stocks can be considered as non-financial measures to the extent that poor inventory management can affect the value of the firm. Indeed, the JIT can avoid the high costs of storage through rigorous coordination with suppliers. Then, productivity reflects the non-financial aspect and it measures the ratio of outputs produced in relation to inputs consumed. This concept is generally used to characterize the efficiency that means the ability of a firm to produce at lower cost. Moreover, innovation (flexibility) is considered the engine of value creation as firms are constantly seeking sources of differentiation through innovation work in succession. Delivery times are also an indicator of non-financial performance since the delivery reliability is critical for customers. Finally, skills and attitudes of the company personnel are performance indicators relevant to the extent that the operation of the business relies on human capital.

\section{Quantifying the impact of tax incentives on financial performance of exporting firms:}

To quantify the impact of taxation on the financial performance, we tried to investigate the two criteria for measuring performance. Indeed, the questionnaire survey about sixty exporting firms relates to measuring the impact of tax incentives on financial performance of companies using non-financial measures of performance such as certification, innovation, personnel, environment, flexibility and quality, as key factors and determinants of competitiveness and performance of an export company. This investigation has attempted to supplement the results of the approach based on the estimate of the net income and the output (two financial measures of performance) using information provided by the assessments of 14 firms over the period from 2001 to 2003.

The estimate of the profitability of a business is a good indicator to measure the effectiveness of the company through its production function. Therefore, the calculation of the profitability of a company must be accompanied by a comparison with its level of profitability with that of its main competitors. Indeed, a company may very well be profitable, but reveal a level of profitability below that of its competitors. Thus, high profitability allows the company to increase its ability to internal and external funding and is used to sustain high growth.

By placing the tax incentives in the vector of determinants of performance (table1 in annex), we note that taxation affects the performance of the firms. In fact, it ranks seventh on a scale with 10 items listed in the table above. It is interesting to note that the financial measures of performance are most used in practice. As the disk non-financial measures are of limited use, and if they exist, they are generally poorly exploited.

\subsection{Justification for the choice of sector EMI}

IME sector is one of the leading sectors of the Tunisian economy and comes after the textile clothing (ITC) in terms of value but it ranks first in terms of growth rate relative to the total of exports thus occupying $23 \%$ of total Tunisian exports. Note that the choice of EMI is retained in our work because it is the only sector that meets the best in 
regards to financial impacts of tax incentives. To locate the evolution of exports sector engineering industries relative to total exports, we determined econometrically the rate of increase of exports as well as the total EMI. The results of this adjustment are given below:

$$
\begin{aligned}
& \log (\mathrm{XIME})=\begin{array}{c}
287.2+0.147 \times \mathrm{T} ; \quad \mathrm{n}=17 ; \mathrm{R}^{2}=0.98 \\
(37.8)(38.7)
\end{array} \\
& \log (\mathrm{XT})=\begin{array}{c}
192.3+0.100 \times \mathrm{T} ; \quad \mathrm{n}=17 ; \mathrm{R}^{2}=0.98 \\
(32.4)(33.8)
\end{array}
\end{aligned}
$$

Where:

XIME : Exports Sector EMI, XT : total exports and $\mathrm{T}$ represents the time.

It shows that exports of sector products EMI rose at a rate of $14.7 \%$ per annum over the period from 1988 to 2004, a faster evolution than that recorded for total exports $(10.0 \%)$.

The graphic representation (Fig 1) of changes in rates of export growth in the sector in question and total confirms the significant difference detected previously using the average growth rate.

Indeed, the fit log-linear export sector based on EMI's total exports gave the following result:

$$
\begin{aligned}
& \log (\mathrm{XIME})=5.848+1.454 \log (\mathrm{X}) \quad \mathrm{R}^{2}=0.99 \\
& \text { ( 19.60) (41.97) }
\end{aligned}
$$

This evolution has resulted in an elasticity of exports of the sector in question greater than 1 (or 1.454) compared to total exports, which confirms the idea of the booming of the EMI's sector in Tunisia over the period analyzed.

\subsection{Impact of tax reform on the sector's total exports EMI}

A very basic question can be elaborated at this level: The business tax reform in Tunisia since the year 1994 (the introduction of the code of fiscal incentives) has had a major impact on export promotion of the EMI' sector?

On this question opinions differ. Some view as shown in the questionnaire, that we submitted on a sixty exporting firms, tax incentives were not up to the expectations of exporting companies and therefore should not expect statistically significant effects on the development of export. Others admit they have benefited from tax benefits granted by the state to increase their market share in exports. This subdivision is within the context of this issue by seeking to provide some answers to this question. To do this, we try to estimate an export supply function incorporating more traditional determinants, tax reform:

$$
\mathrm{LXIME}_{\mathrm{t}}=a_{0}+a_{1} \mathrm{LDM}_{\mathrm{t}}+a_{4} \mathrm{LPXR}_{\mathrm{t}}+a_{6} \mathrm{RF}_{\mathrm{t}}
$$

Where: LXIME : Evolution of exports of the EMI's sector in logarithm, LDM : Global demand in logarithm, LPXR : Relative export price (compared with the general price index) in logarithm and RF : Tax Reform. This is a dummy taking value 1 from 1994 to 2004 and zero otherwise.

Prior to the estimation of this equation, we give below some characteristics of variables used in this model. The estimation of the results of the model above by ordinary least squares method gives directly the elasticity for the explanatory variables mentioned above and is as follows:

$$
\begin{aligned}
& \mathrm{LXIME}_{\mathrm{t}}=1.914+0.498 \times \mathrm{LDM}_{\mathrm{t}}+4.234 \times \mathrm{LPRX}_{\mathrm{t}}+0.097 \times \mathrm{RF}_{\mathrm{t}} \\
& (0.97) \quad(2.08) \\
& \mathrm{n}=17 ; \quad \mathrm{R}^{2}=098 \quad ; \quad \mathrm{DW}(4.17)=1.73 \quad ; \quad \mathrm{F}(3.13)=387.4
\end{aligned}
$$

The statistic of Fisher is equal to 387.4, implying that the model is highly significant. In addition, the Durbin-Watson implies the absence of autocorrelation of order 1 residues. In addition, according to Student ratio in parentheses, coefficients associated with the impact of tax reform (variable of interest in our study) and the export price relative are highly significant, indicating that the impact of global demand is significant at $5.8 \%$. We also note the high elasticity of exports sector in relation to EMI export prices relative (Fig 2). Indeed, as shown the curve tracing the growth of export prices of the EMI sector is, except for 1995, above that of the general index of producer prices. The examination of the chart above shows a strong correlation between the price indices: general and export, which shows largely that general price index is explained largely by the price index Export of EMI.

\subsection{Financial implications of tax incentives: empirical validation using an econometric model}

Using data provided by accounting balance sheets and income statements of a sample of 14 exporting companies in Tunisia we have determined econometrically the impact of tax rates on the level of output and earnings. The period 
of analysis is three years (2001-2003)

\subsubsection{The model}

\section{Dependent variables}

We distinguish two kinds of dependent variables, namely, net income (income minus expenses), and the output (sales plus the change in inventories). Let us remember that the output is a variable that was retained by Michel Devreux (1989) in an attempt to explain the investment behavior of firms in the UK. Indeed, the level of expected output per firm dictates its level of investment. Thus, a substantial increase in output leads to increased investment.

\section{Independent variables}

The tax rate: The tax rate is defined as follows:

$$
\mathrm{TIS}=\frac{\mathrm{IS}}{\mathrm{BN}+\mathrm{IS}}
$$

Where, IS: the corporate income tax, and NI: net income. It is expected a negative relationship between tax rates and the level of production to the extent that a higher tax rate increases the tax paid by the taxpayer, which increases production costs.

The debt capacity: This variable was used by Jorgenson (1964) in its investment model. Indeed, the greater the debt capacity of the company, the higher the firm's capability to achieve its investment projects, and it provides a better production. We expect a positive relationship between debt capacity and output levels. The independent variable may arise as follows:

$$
\text { DEBCAP }=\frac{\text { DLMT }}{\text { TOTASSETS }}
$$

Where: DEBCAP : Debt capacity, DLMT : Debt long and medium term and TOTASSET $\subseteq$ : Total assets

The stock of capital: Capital stock measured by net fixed assets. Indeed, we expect a positive relationship between this variable and the level of output. To analyze the impact of fiscal incentives on the profitability of exporting firms, we then explain the net profit (respectively output) by its determinants, namely, the stock of capital, personnel expenses, debt capacity and tax rates.

\subsubsection{The estimation results}

The estimation of this model by the method of least squares was performed.

$$
\begin{array}{rlrr}
\mathrm{BN}= & 9918907+0.305 \times \text { stodk } & 0.457 \times \text { persodarg }+1426541 \times \text { depcap } & 4.254254 \times \text { is } \\
(2.35) & (5.97) & (1.51) & (3.95)
\end{array}
$$

We note that all coefficients are statistically significant, except those associated with staff costs. Indeed, the T-student statistics in absolute value is greater than 2. In addition, the model is significant as a whole. Thus, the calculation of the elasticity of net income from the tax rate has registered a net profit equal to (- 0.07). All things being equal, an increase of $10 \%$ tax rate would decrease by $0.7 \%$ in net income.

Similarly, we made an adjustment in logarithm of output in the logarithm of capital stock, financial performance, staff costs in logarithms and the tax rate. The estimated equation is as follows: Loutput $=6.6488+0.2671 \times$ Lstodk $+0.1939 \times$ profit+0.359 $\times$ L perschang $3.116 \times$ is

$$
\begin{array}{llll}
(2.031) & (0.106) \quad(0.454) \quad(0.209) \quad(1.440)
\end{array}
$$

This model allows us to determine the impact of a change in the tax rate on output. Indeed, an increase of $1 \%$ tax rate would reduce the output of $-0311 \%$.

\section{The perception of tax incentives: Multivariate Analysis}

It refers to methods of analyzing data collected in cross section using a questionnaire. This work aims to analyze the impact of tax incentives on the profitability and performance of exporting firms. To do this, we proceeded to collect the information necessary for this analysis, by a questionnaire. The observed sample size is equal to 60 exporting companies fully or partially operating in the area of EMI, or nearly $3 \%$ of the total population studied companies (2621 companies). We note that in order to examine reliability and consistency among the responses against each item in the questionnaire, we have used Cronbach Alpha which is equal to 0.86 .

\subsection{Cluster Analysis}

We seek to create homogeneous groups of companies from a range of variables relating to profitability, performance 
and competitiveness of Tunisian exporters as part of the sample, namely the turnover and certification. To do this, we use cluster analysis in an ascending hierarchy process based on the criterion of Ward aggregation. This is from the individuals themselves and try to classify them gradually in the likeness of their responses to selected variables, namely the turnover and certification. From the results of the typology, we create a new variable indicating for each individual, number, and group affiliation. This new variable will be crossed (via discriminatory analysis) by some other variables in the questionnaire to describe precisely the profile of each group. The result of this classification is represented as a classification tree. The development of this tree here is ascending by successive groups of individuals (Graph 3). We note that it is between the two last nodes that the increasing index level is the strongest. By operating a disconnection between these two nodes, we define a partition into two classes. To have a valid classification, we made a break in the hierarchical tree at a level that ensures the lowest loss of inter-class inertia and corresponding to a limited number of homogeneous groups (or classes). To identify the components of one of these classes, simply list the basic elements that are accessed by following down the ramifications of one arm severed by this cut. Thus, in the case of the cut defined above, we obtain the following two classes:

Group $\mathbf{N}^{\circ} \mathbf{1}$ (Number of affected individuals in this class): 59-60-44-57-58-56-29-30-8-27-39-10-35-4-2-36-38-52 $-53-47-51-3-48-28-42-11-32-12-14-6$.

Group No2: 22-23-54-55-43-41-15-24-20-16-1-25-37-46-21-26-33-5-49-13-40-7-45-31 -34-19-9-18-50-17.

The analysis of the similarity between the firms surveyed can be made by examining the scatter plot individuals resulting from the application of Factor Analysis of Multiple Correspondence (MCA). This analysis confirms the results given by the hierarchical classification. Indeed, the graphical representation of the two groups identified by the MCA according to the coordinates corresponding factor of individuals is represented in the Graph 4. We see clearly a sharp distinction between the two coordinated groups of individuals (represented by their serial number) on the first two factorial axes explaining alone $56 \%$ of the total inertia. Note that individual No. 41 appears to be unusual and require special treatment. The description of groups can be identified using the frequencies of variables for each class. By examining these frequencies, we note that the first class formed by enterprises whose turnover for export is the highest (above 75\%) actually corresponds to firms that benefit from tax and social benefits. Indeed, officials of these firms have benefited from fiscal incentives granted by government. We can then call this first class as that of firms' performance "with a turnover of export relatively high, and learned to enjoy the tax benefits available to them by the state. The second class includes the remaining firms of their size are unable to receive proper tax benefits. These firms are characterized by lower frequencies in the degree of adherence to the Tunisian system of tax incentives.

\subsection{Discriminant analysis}

The purpose of this analysis is to determine the variables most discriminating vis-à-vis two classes defined using cluster analysis. In other words, we seek to determine which group owns a company from its explanatory characteristics. The assignment of these two classes necessarily involves the eligibility of the business tax incentives. We are interested in obtaining the best possible discrimination with the minimum of variables, possibly for reasons of performance, robustness and reliability of results. Statistics such as Wilks' lambda, the percentage of correctly classified and canonical correlation can serve as a criterion for inclusion or elimination of explanatory variables.

Thus, discriminatory analysis involves four steps:

Step 1: Verify the existence of differences between subgroups

We check whether there are differences between the two groups with three indicators, namely, the mean or variance, Fisher's test and Wilks' Lambda. The results of this analysis we can determine which variables are most discriminating between groups. These searches among the averages, those that have a high value for the first group and compare it with the second group. Consider, for example, incentives in terms of IS and PIT. In this corresponds to an average of 1.8 for the first group and an average of 1.63 for the second group. The same thing occurs at the level of borrowing. Indeed, the first group has an average of 1.83 against a value of 2.00 for group $2 \ldots$ Thus, the variables that differentiate the two groups identified using hierarchical cluster mainly tariffs, the benefits in terms of corporation tax and personal income tax, social contributions, the borrowing, the incentives granted in terms of flow, the incentives as a motivating factor essential gaps and shortcomings.

Step 2: Verify the validity of the study

The overall correlation is given by the table of values associated with linear discriminatory functions. These values can judge the discriminating power of these respective functions. Thus, the first value (ratio of the sum of squared differences between classes on the sum of squared deviations intra-class) equals 0791 .

In addition, canonical correlation, expressing the proportion of total variability attributable to differences between 
the centers of groups (analogous to the decreasing quantity) is equal to 0.665 , worth over $50 \%$. We believe then that the model is reliable as a whole. Finally, the Wilks Lambda distributed according to a law Khi2 with p (k-1) degrees of freedom is equal to 0.558 (below 0.9), which also demonstrates the robustness of the model.

Step 3: Estimated discriminatory function coefficients

We observe the discriminating axes through the table of averages. We note in passing that the signs are arbitrary; only the opposition's signs have meaning. We can write the discriminatory function as follows:

\section{$2.848+0.485 \times \mathrm{IS} / \mathrm{IRPP}+1.377 \times \mathrm{TVA} / \mathrm{DC}+4.08 \times \mathrm{DD}+0.49 \times \mathrm{TFP} /$ FOPROLOS \\ $+0.4 \times$ FORM+0.39 $\times$ REM $\quad 0.36 \times$ COT.SOC +0.52 $\times$ AUTO.FIN +2.20 $\times$ EMPT \\ $+0.28 \times$ CONST.BAT $1.20 \times$ ACQ.EQUIPT + $1.51 \times$ ENCOURSACTIV + 2.84 \\ $\times$ FACT.ESSENT +5.15 $\times$ LACUNES}

For this linear discriminatory function, the most discriminating variables are: tariffs, having benefited from tax and social benefits at the level of borrowing, having received these benefits for the acquisition of equipment and ongoing activity of the company, the incentives are a key motivating factor and motivation and finally the current system of tax benefits and suffers from social inadequacies and shortcomings.

\section{Step 4: Quality of representation}

This is to ensure that the discriminatory function classifies individuals well into sub-groups. For this, we analyze the confusion matrix which includes individuals correctly classified and those misclassified (tab 2). Thus, in our case, 26 elements of group 1 were well classified by the discriminatory function and 4 have been wrong. Similarly, for group 2,12 were correctly reclassified or $82.6 \%$ success. The results of classification according to Bayes rule assignment thus show an apparent rate of well-ranked high (82.6\%), weighted average rate of apparent well-ordered for each group varying from $86.67 \%$ in group 1 ( successful companies) to $75 \%$ for group 2 , with the greatest allocation error. Group 1 is slightly more homogeneous than group 2 .

\subsection{Logistic regression}

Our goal here is to clarify the extent to which predictors are associated with the endogenous variable "successful companies" and can predict this phenomenon. In other words, we seek through this analysis to identify potential predictors. It is worth mentioning that the variable to predict here, belonging to the group of successful companies must be represented by 1 . While the other group, composed of non-performance must be identified with zero. We recall that the purpose of our research is to test the degree of association between tax incentives and the success of EMI sector's export. Logistic regression is then used to address this problem by specifying the extent to which Tunisian exporting firms benefit from tax incentives granted by the state. Examining the results of Logit model estimates show the significant association of the dependent variable (export performance) with the predictors listed above in the context of discriminatory analysis in which we remember those who primarily used to validate our hypotheses : tariffs, having benefited from tax and social benefits at the level of borrowing, having benefited from these advantages for the acquisition of equipment and ongoing activity Business, incentives are a key motivating factor and motivation and finally the current system of tax benefits and suffers from social inadequacies and shortcomings. Checking the strength of association of the model is done by examining the Nagelkerke (representing the variance explained by the model). Thus, the model explains $78 \%$ of the variance in the dependent variable, here the export performance.

\section{Conclusion}

EMI sector in Tunisia is growing at a pace somewhat important. Indeed, we determined econometrically the rate of increase in exports of both EMI that total by taking into account the period from 1988 until 2004. We noted that the exports of sector products EMI rose at a rate of $14.7 \%$ per annum over the period from 1988 to 2004, a faster evolution than that recorded for total exports $(10.0 \%)$, confirming the idea of the booming sector EMI in Tunisia over the period analyzed. The estimates of a discriminatory function and the logit model confirms the results given by the econometric analysis to know that tax incentives are not without effect on the behavior of production and export of Tunisian companies. However, methods of data analysis that we used are, despite their attractive, relatively exploited in the empirical literature. Furthermore, by examining the results of this analysis we note that the survey has allowed us to emphasize, to a large extent, a strong involvement of the Tunisian Government for assistance of Tunisian export's firms to improve their competitiveness through the development of a free trade zone with the European Union. Thus, this broad consensus on the prospects and opportunities offered by the government revolves around the tax incentives granted by them to stimulate investment and promote exports as the motor of the Tunisian economy. In this sense the Tunisian Government has embarked on a process of reforms to establish an efficient tax 
system. Tax incentives appear to be an essential component for survival and development of export business. They were considered by most respondents as a source of motivation but in the long term. In terms of drawbacks, they are manifested first by the intensity of international competition especially of Asian products that may invade the world; sample firms have raised other problems. At government level, exporting firms $(60 \%)$ suffer from the slowness of administrative procedures. They are also dissatisfied with the lack of raw materials. So the industry is relatively energy intensive. The costs of services continue to be judged as such high. The firms surveyed are dissatisfied with the cost of airline fares that are increasingly considered high. In short, it is noted that the IME sector is an emerging sector in our country. Indeed, labor is not sufficiently qualified. It is clear that in spite of the efforts made by public authorities to promote exports, the current system of tax incentives suffers from several weaknesses and shortcomings. In this regard, to ensure a high level of export performance, respondents argue that we should not be content with only tax incentives, hence the need to develop new approaches able to confer a much more important. In fact, the modernization of export firms belonging to the EMI sector, improving their management and expanding their competitive ability are essential factors to increase profitability and gain new markets. It must be recognized just as some exporters (specifically those belonging to the group both identified by the hierarchical classification) does not give full satisfaction for several reasons. Indeed, several exporters have failed to control the quality component. Moreover according to the survey questionnaire revealed that the number of firms certified ISO 9001 is very limited. Meanwhile we find that exporting firms interviewed are becoming small pus (31.67\% have a turnover of less than $25 \%$ ). This reflects a major deficiency which can hinder the expansion of productivity, improvement outpourings of these shortcomings, the respondents proposed to think about reducing the rate of employer contributions to the NSSF. Others intend to develop other tax incentives such as bonuses according to the CA for export. This study thus demonstrates the advantages and limitations of performance analysis by a questionnaire. It follows the movement of growing interest in the possibility offered by the survey data which are a significant source of quantitative information provided by the administration official statistics. The results are of course conditioned by the representativeness of the sample, and the refusal of some leaders to respond to questions.

\section{References}

Boadway. R. (1979). Investment incentives, corporate taxation, and efficiency in the allocation of capital. Available: http://www.jstor.org/pss/22320475. [Online] (September 12, 2009).

Devereux. M. (1989). A Positive Theory of Inflation and Inflation Variance. [Online] Available: http://ideas.repec.org/s/oup/ecinqu.htm 1 (August 22, 2010).

Frydman.R, Gray.C, Hessel \& Rapaczynski. A. (1999). When Does Privatization Work? The Impact of Private Ownership and Corporate Performance in Transition Economies. Ideas.uqam.ca. [Online] Available:http://home.cergeei.cz/hanousek/jel_survey/Table\%205/Frydman,\%20Gray,\%20Hessel\%20and\%20Rapac zynski\%20(1999).pdf (July 11, 2011).

Gurría.A. (2009). L'amélioration de l'efficacité des systèmes fiscaux des pays en développement et la nouvelle frontière de la politique de développement. L'OCDE. [Online] Available: www.oecd.org (March 10, 2011).

Houdebine.M et Bensaid.A.T. (1999). L'investissement direct et les entreprises françaises. [Online] Available :http://www.insee.fr/fr/ffc/docs_ffc/Es326F.pdf (December 6, 2011).

Hoyt. B. (2007). Tax Havens Today, the Benefits and Thes Pitfalls of Banking and Investing Offshore. [Online] Available: http://www.hoytbarber.com/tax-havens-today (April 12, 2010).

Ittner .C.D et Larcker.D.F. (2003). Coming up short on non financial performance measurement. [Online] Available: http://maaw.info/ArticleSummaries/ArtSumIttnerLarcker03.htm (July 22, 2010).

Jochen. M \& Birk.A. (2006). Employment and growth effects of tax reforms. [Online] Available: http://www.sciencedirect.com/science/article/pii/S0264999306000459 (October 7, 2009).

Jorgenson. D.W. Jorgenson. (1967).The theory of investment behavior. [Online] Available: http://www.economics.harvard.edu/faculty/jorgenson/complete_publications_jorgenson (Apri120, 2009).

Julien P.A, Toulouse J.M, Ramangalahy C. et Morin. (1998). Comportements d'information, compétitivité et performance des PME $\quad$ exportatrice. http://christopheschmitt.free.fr/site/contenu/page_a_modifier/internationaux.html (July 13, 2008).

King. M.A. King. (1974). Taxation and the cost of capital. [Online] Available: http://www.restud.com/ (February 8, 2008).

Laffont J.J. et Tirole J. (1991). Privatisation and incentives. [Online] Available: http://heinonline.org/HOL/LandingPage? collection=journals\&handle=hein.journals/jleo7\&div=33\&id=\&page 
(March 31, 2008).

Lebas. M. (1995b). Oui il faut définir la performance. [Online] Available : www.compta-online.com/revue-francaise-comptabilite-t260 (June 2,2008).

Mihir A. Desai, C. Fritz Foley \& James R. Hines Jr. (2006) "Taxation and Multinational Activity: New Evidence, New Interpretations. [Online] Available : http://www.bea.gov/scb/pdf/2006/02february/0206_mnc.pdf (October 25, 2008).

OCDE. (2008). Incidence de l'impôt sur l'investissement direct étranger. [Online] Available: http://www.oecd.org/dataoecd/16/36/40251026.pdf (October 2, 2010).

Ramangalahy C. (2002). Richesse des sources d'information et performance des PME exportatrices. [Online] Available : http://web.hec.ca/airepme/images/File/2002/196FA\%20-\%20Charles\%20Ramangahaly.pdf (September 22, 2010).

Richard S. (2003). An empirical study of the impact of corporate taxation on the global allocation of foreign direct investment: a broad tax attractiveness index approach. [Online] Available: http://cmsold.cass.cn/show_News_e.asp?id=16744 (June 12, 2009).

Robert S Kaplan \& David P Norton. (2001). Transforming the balanced scored from measurement to strategic management [Online] http://www.qa.au.edu/page2/research/BSCTranslatingBSCPerfMgtToStrategicMgtPt1.pdf

Sandmo. A. (1974). Investment incentives and the corporate income tax. [Online] Available: http://ideas.repec.org/a/ucp/jpolec/v82y1974i2p287-302.html (July 01, 2009).

Shank J.K. et Govindarajan.V. (1995). Gestion stratégique des coûts Les éditions d'organisation. [Online] Available:http://lipsor.cnam.fr/servlet/com.univ.collaboratif.utils.LectureFichiergw?ID_FICHIER=1295877018205 (november11, 2010).

Stiglitz. J.E. Stiglitz. (1985). Credit markets and the control of capital. [Online] Available : http://www.sciencedirect.com (April 08, 2010).

Stone.A. (2008). De l'efficacité des incitations fiscales pour promouvoir l'investissement. [Online] Available: http://www.oecd.org/dataoecd/1/40/40560300.pdf (July 17, 2009).

Strulik.H. (2003). Capital tax reform, corporate finance and economic growth and welfare. [Online] Available: $\mathrm{http}: / /$ econpapers.repec.org/article/eeedyncon/v_3a28_3ay_3a2003_3ai_3a3_3ap_3a595-615.htm (January 05, 2011).

Yonah. R. S. (2006). Corporate social responsibility and strategic tax behavior. [Online] Available: http://papers.ssrn.com/sol3/papers.cfm?abstract_id=944793 (July 12, 2010)

Table 1.

\begin{tabular}{|l|l|l|}
\hline Determinants of performance & Score & Rank \\
\hline Company size & 7.7 & 9 \\
\hline Flexibility & 9.5 & 1 \\
\hline Human ressources & 9.4 & 3 \\
\hline Quality and certification & 9.3 & 4 \\
\hline Time & 9.1 & 5 \\
\hline Innovation & 8.8 & 7 \\
\hline Technology & 9.5 & 1 \\
\hline Information System & 9.2 & 6 \\
\hline Tax incentives & 8.8 & 7 \\
\hline
\end{tabular}

Déterminants of performance 
Table 2 .

\begin{tabular}{|c|c|c|c|c|c|}
\hline & & & Class & (s) & Total \\
\hline & & Ward Method & 1 & 2 & \\
\hline & & 1 & 26 & 4 & 30 \\
\hline & & 2 & 4 & 12 & 16 \\
\hline & Effectif & $\begin{array}{l}\text { unclassified } \\
\text { comments }\end{array}$ & & 2 & 14 \\
\hline & & 1 & 86,67 & 13,33 & 100 \\
\hline & & 2 & 25 & 75 & 100 \\
\hline Original & In $\%$ & $\begin{array}{l}\text { unclassified } \\
\text { Comments }\end{array}$ & 85,71 & 14,29 & 100 \\
\hline
\end{tabular}

Confusion matrix

\section{Exportations (on \%): IME / TOTALS (X)}

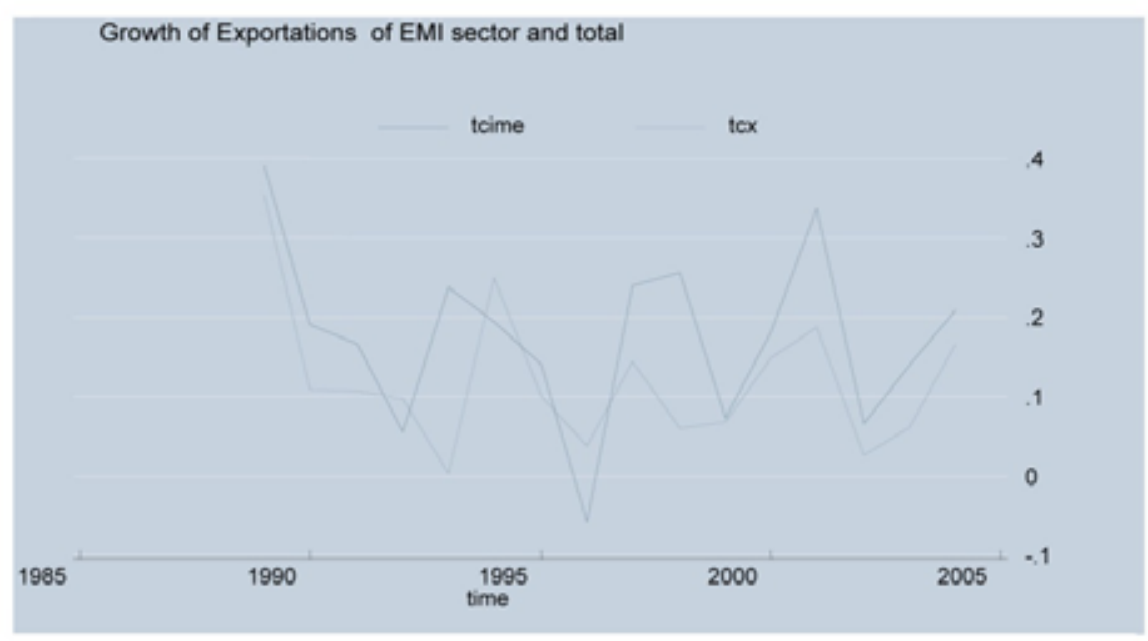

\section{Graph 1.}

IGP / export price of EMI

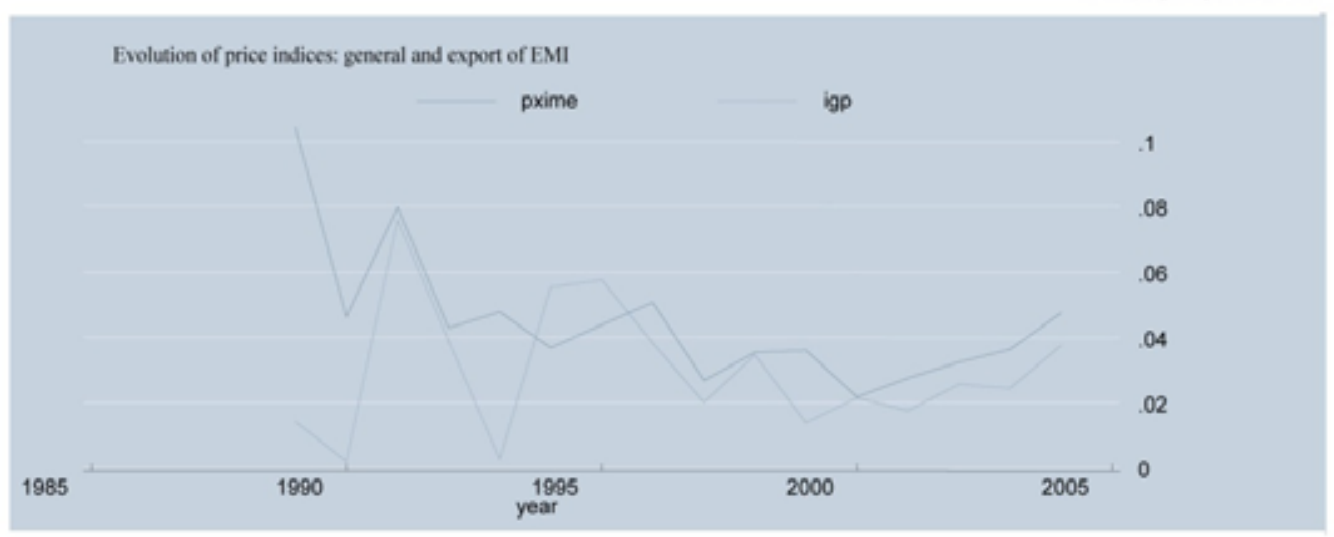

Graph 2. 


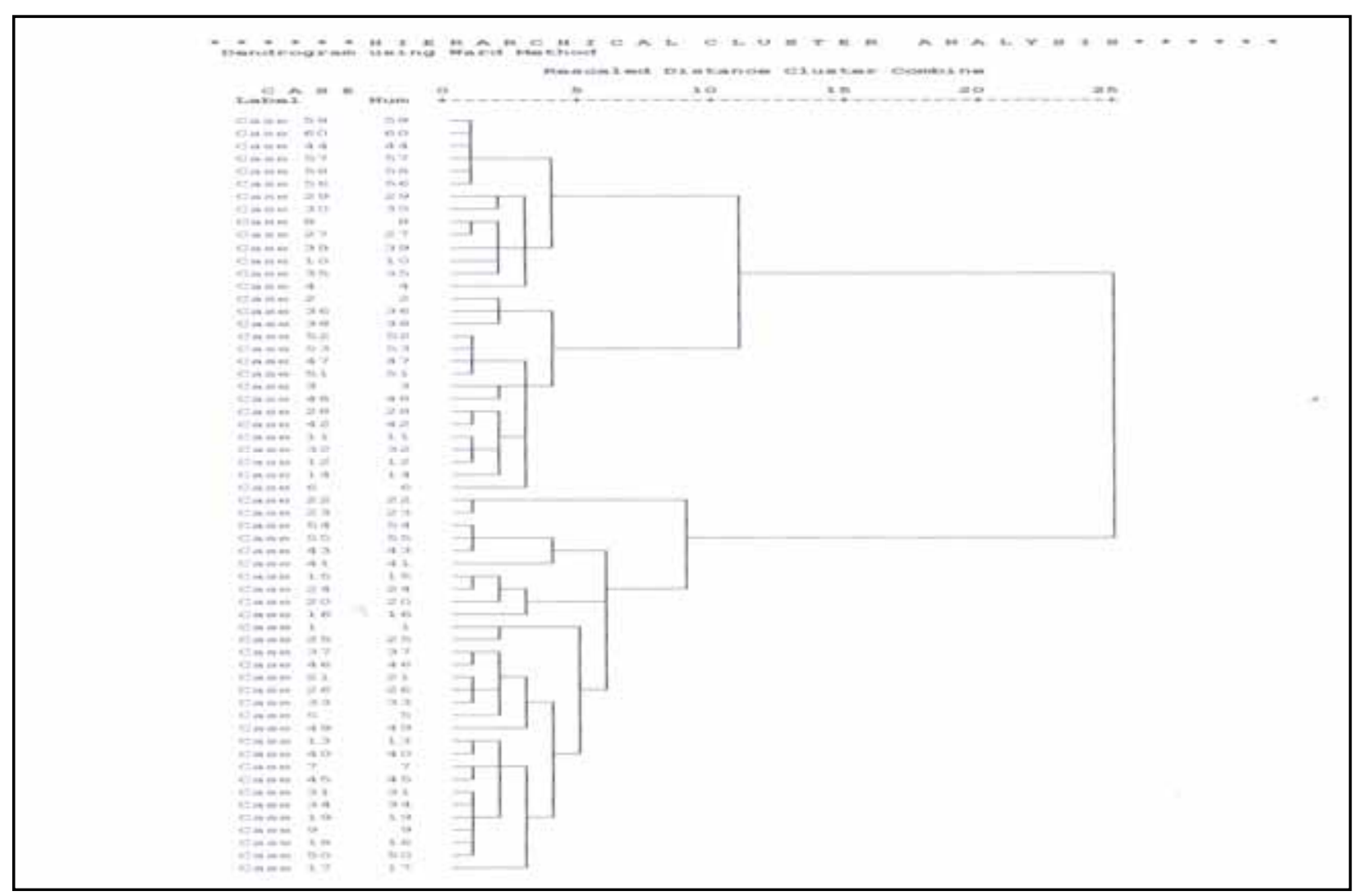

Graph 3. Hierarchical classification

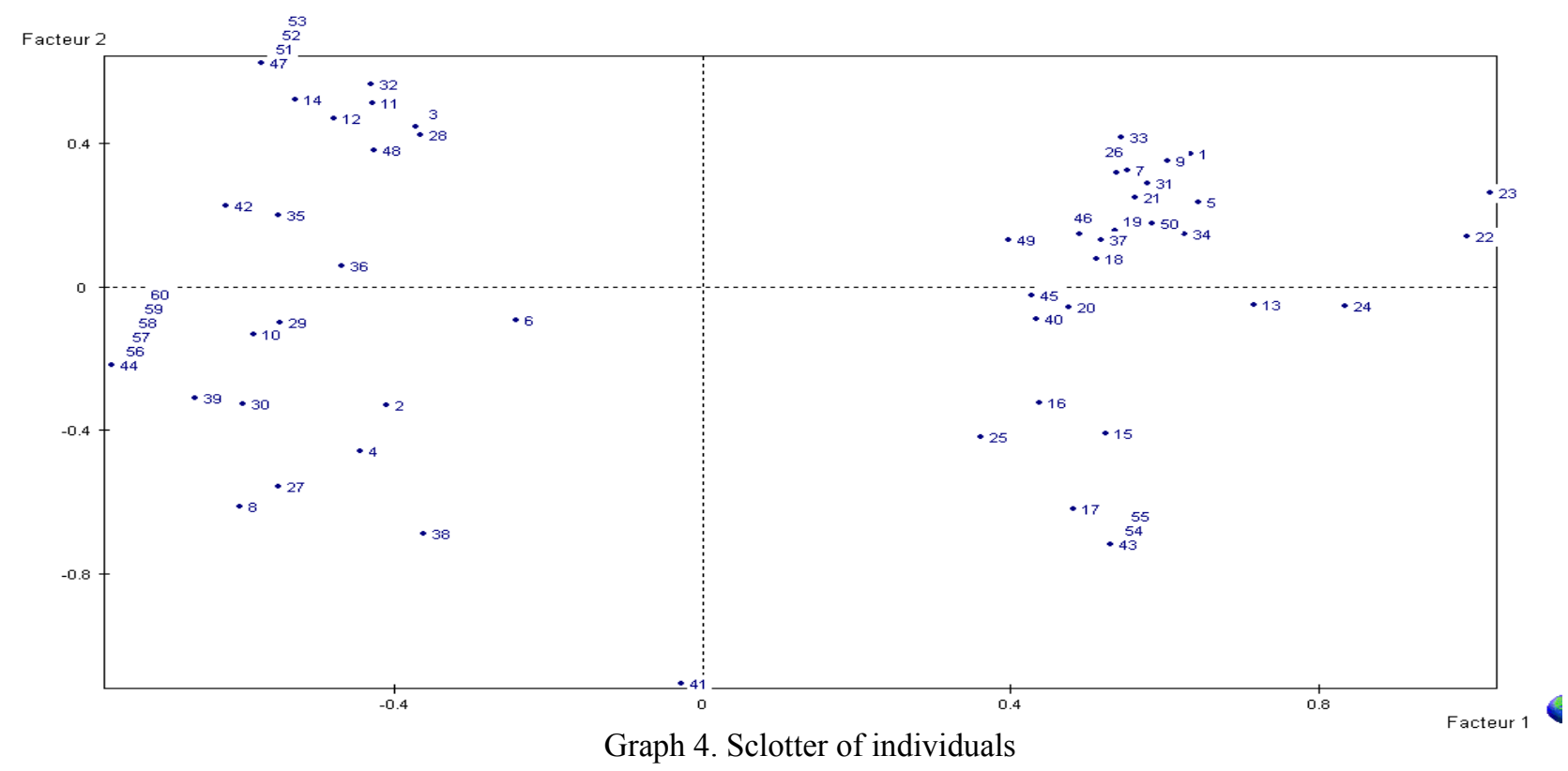

